\title{
Expression of a retinoic acid response element-hsplac $Z$ transgene defines specific domains of transcriptional activity during mouse embryogenesis
}

\author{
Janet Rossant, ${ }^{1,2}$ Ralph Zirngibl, ${ }^{1}$ Dragana Cado, ${ }^{1}$ Mary Shago, ${ }^{2,3}$ and Vincent Giguère ${ }^{2,3}$ \\ ${ }^{1}$ Division of Molecular and Developmental Biology, Samuel Lunenfeld Research Institute, Mount Sinai Hospital, Toronto, \\ Ontario, M5G 1 X5 Canada; ${ }^{2}$ Department of Molecular and Medical Genetics, University of Toronto, Toronto, M5S 1A8 \\ Canada; ${ }^{3}$ Research Institute, Hospital for Sick Children, Toronto, Ontario, M5G 1X8 Canada
}

\begin{abstract}
Treatment with retinoic acid (RA) is known to produce complex teratogenic effects in vertebrates, and its presence in the developing embryo as an endogenous substance has led to the suggestion that RA might be a natural morphogenetic agent. Although our understanding of the molecular mechanism of RA action has improved considerably with the identification of nuclear receptors for RA (RARs) and RA-responsive genes, the exact relationship between the proposed morphogenetic activity of RA and its teratogenic effects remains to be characterized. Here, we show that a RA response element (RARE) present in the RAR $\beta$ gene can direct specific spatial and temporal expression of an hsplacZ transgene during mouse embryogenesis. In the early embryo, the transgene is expressed in a specific anterior-posterior domain that is completely obliterated by treatment of pregnant mice with teratogenic doses of RA. The expression of the transgene becomes more restricted as organogenesis progresses and mimics closely the reported expression of the RAR $\beta$ gene. These results suggest that, in vivo, some of the morphogenetic effects of RA could be mediated through localized transcriptional activity controlled by the various RARs. The specific pattern of expression of the RAREhsplac $Z$ transgene does not correlate with the proposed sites of action of RA as defined by its teratogenic effects but does support a role for RA in early anterior-posterior patterning along the body axis.
\end{abstract}

[Key Words: Retinoic acid; morphogen; nuclear receptor; transgene; embryo; mouse]

Received April 15, 1991; revised version accepted May 31, 1991.

Retinoic acid (RA) may act as a regulator of differentiation at various stages of vertebrate embryogenesis. In particular, the results of exogenous RA treatment have implicated RA in anterior-posterior $(\mathrm{A} / \mathrm{P})$ patterning both along the body axis and in the developing limb bud. The development of axial structures in the Xenopus embryo can be affected by RA treatment; progressive reduction in anterior structures occurs with increasing RA dose (Durston et al. 1989; Sive et al. 1990; Ruiz i Altaba and Jessell 1991). A variety of abnormalities, including neural tube defects, craniofacial abnormalities, and limb defects, have been reported after treatment of pregnant mammals with RA (Langman and Welch 1967; Morriss 1972; Geelen 1979; Kochhar 1985; Lammer et al. 1985). Local application of RA to the developing chick limb bud can cause duplication of the normal A/P pattern (Tickle et al. 1982, 1985) and can respecify the positional memory of the blastema in both the proximodistal and anteroposterior axes during limb regeneration in urodeles (for review, see Brockes 1989).

As with any putative morphogenetic agent, demonstration that exogenous treatment with RA has develop- mental effects is not sufficient to prove that the substance plays a role in normal development. The factor must be shown to be distributed in the embryo in a temporal and spatial pattern consistent with its proposed action, and there must be accessory molecules present to allow transduction of the morphogenetic signal. The distribution of RA within the embryo is not well understood because of the difficulty in localizing RA in situ. High-performance liquid chromatography (HPLC) measurements have shown that RA is present in the developing chick (Thaller and Eichele 1987), mouse (Satre and Kochhar 1989), and Xenopus (Durston et al. 1989). However, only in the chick limb bud is there evidence for a graded distribution of RA consistent with a possible role in specifying limb pattern in the undisturbed embryo (Thaller and Eichele 1987; Eichele 1989). Hensen's node in the chick embryo (Hornbruch and Wolpert 1986) and the floor plate of the rat neural tube (Wagner et al. 1990) can also induce pattern alterations when grafted to the chick limb bud, suggesting that these tissues may be sources of RA production in vivo. This is supported by evidence that the floor plate can metabolize retinol to 
RA in vitro (Wagner et al. 1990). However, although Hensen's node, the notochord, and the floor plate have been shown to play critical roles in $\mathrm{A} / \mathrm{P}$ and dorsal-ventral patterning in the developing nervous system (Hemmati-Brivanlou et al. 1989; Hirano et al. 1991; Yamada et al. 1991), there is no direct evidence that these roles are mediated by RA.

The recent discovery that RA interacts with nuclear receptors related to the steroid and thyroid hormone receptors, a family of proteins that function as ligand-dependent transcription factors, suggests that the morphogenetic functions of RA may result, at least in part, from activation of developmentally regulated genes by RA receptor (RAR) complexes. Several loci encoding RAR isoforms have been identified in mammals-RAR $\alpha$ (Giguère et al. 1987; Petkovitch et al. 1987), RAR $\beta$ (Benbrook et al. 1988; Brand et al. 1988), and RAR (Krust et al. 1989; Zelent et al. 1989; Giguère et al. 1990a; Ishikawa et al. 1990; Kastner et al. 1990)-as well as novel nuclear receptors known as RXRs (Mangelsdorf et al. 1990|, which are distantly related to RARs and respond to high concentrations of RA. The RARs show spatially restricted distribution patterns during embryogenesis, which have led to speculation on a variety of roles for RA in developmental processes (Dollé et al. 1989, 1990; Osumi-Yamashita et al. 1990; Ruberte et al. $1990,1991)$. An additional feature of retinoid physiology is the existence of a distinct class of molecules, the cellular retinol- and RA-binding proteins (CRBPs and CRABPs), which may modulate the accessibility of RA to the receptors (Maden et al. 1988, 1989a). Representatives of each binding protein also show spatially restricted patterns of expression in the embryo (Dollé et al. 1989, 1990; Maden et al. 1989b, 1991; Perez-Castro et al. 1989; Vaessen et al. 1989, 1990; Dencker et al. 1990; Ruberte et al. 1990, 1991). The complexity of retinoid action was demonstrated further by the recent finding that specific interactions between RARs and other nuclear proteins, including the thyroid hormone receptors and the AP-1 transcription factor, can modulate their transcriptional activity (Glass et al. 1989, 1990; Schüle et al. 1990a, 1990b).

Given the diversity of auxiliary factors involved in the transduction of the RA signal, it is difficult to deduce the actual sites of action of RA within the intact embryo. A more direct means of assessing the levels of active RAR complexes is needed during embryogenesis. These levels will depend on the amount of free RA available to the specific receptors and the presence or absence of other regulatory proteins within a particular cell. As with other enhancer-binding proteins, nuclear receptors act as transcription factors by binding to specific DNA recognition sequences generally located upstream of responsive genes (for review, see Evans 1988; Green and Chambon 1988). Although RARs can activate gene expression through binding to thyroid hormone response elements (Umesono et al. 1988), a much more specific and potent RA response element (RARE) has been identified recently within the promoter of the RAR $\beta$ gene /de The et al. 1990; Sucov et al. 1990). This RARE is essential for
RA induction of the RAR $\beta$ gene and, when linked to heterologous promoters, can confer transcriptional activation via all three RARs (Sucov et al. 1990). If the expression of the RAR $\beta$ gene were solely autoregulated by its ligand, the sites of high expression of RAR $\beta$ in the embryo might, in themselves, provide a readout of the major sites of transcriptional activation by RA. However, it is likely that the RAR $\beta$ gene is also subject to $\mathrm{RA}$-independent tissue-specific regulation. More direct information on the sites where RA is present in the embryo in a form capable of binding to receptors and activating transcription should be provided by introduction of a vector consisting of the RARE upstream of a minimal promoter-reporter gene construct into transgenic mice. Here, we report that a transgene with three copies of the RARE upstream of a mouse hsp681acZ construct (Kothary et al. 1989) was expressed in a specific A/P domain in the embryo following the onset of neurulation. The pattern of transgene expression overlapped with, but was not identical to, the reported expression pattern of the RAR $\beta$ gene (Ruberte et al. 1990, 1991). This domain was obliterated by exogenous treatment with RA. In the later embryo, expression of the transgene became more restricted and resembled more closely the reported expression of the RAR $\beta$. The pattern of expression in early embryogenesis is consistent with a role for RA in early A/P patterning along the body axis but does not support a role in primary mesoderm migration or initiation of neural induction.

\section{Results}

In vitro response of the RAREhsplac $\mathrm{Z}$ vector to $R A$

The RARE described as part of the upstream elements of the RARE $\beta$ gene has been reported to confer RA responsiveness on heterologous promoters in the presence of functional RAR molecules in vitro (de Thé et al. 1990; Sucov et al. 1990) but not to respond to steroid and thyroid hormone-receptor complexes. Three copies of the 34-bp oligonucleotide encoding the RARE (Fig. 1A) were inserted upstream of the promoter from the mouse heatinducible hsp68 gene (Perry and Moran 1987) in the vector phspPTlacZpA (Kothary et al. 1989), as shown in Figure 1B. Previous studies had shown that the parent vector has no detectable basal activity in transgenic mouse embryos but is activated widely by heat shock (Kothary et al. 1989). It can also be activated in very specific patterns by either defined heterologous enhancer elements (Tuggle et al. 1990) or unknown elements at the site of integration of the transgene (Gossler et al. 1989).

To test for RA inducibitity of the reporter construct, the RAREhsplacZ vector was transfected into F9 cells, which were then tested for $\beta$-galactosidase activity in transient assays with and without prior RA treatment. The control vector, phspPTlacZpA, lacking the RARE, was also tested. RA could induce $\beta$-galactosidase activity ( $\sim 12$-fold) only when F9 cells (Fig. 1C) were transfected with the reporter plasmid containing the RARE. Transfection of F9 or CV-1 cells with the thyroid hormone 
A

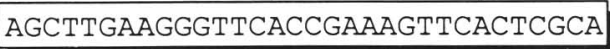

B

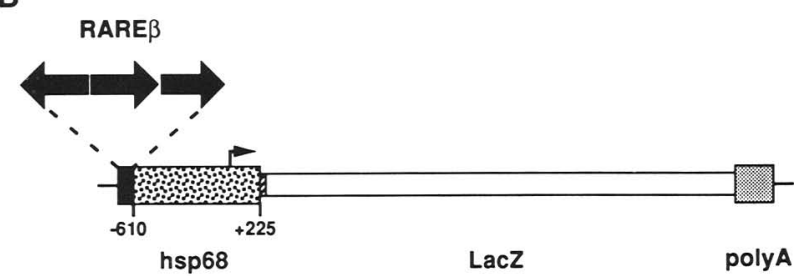

C

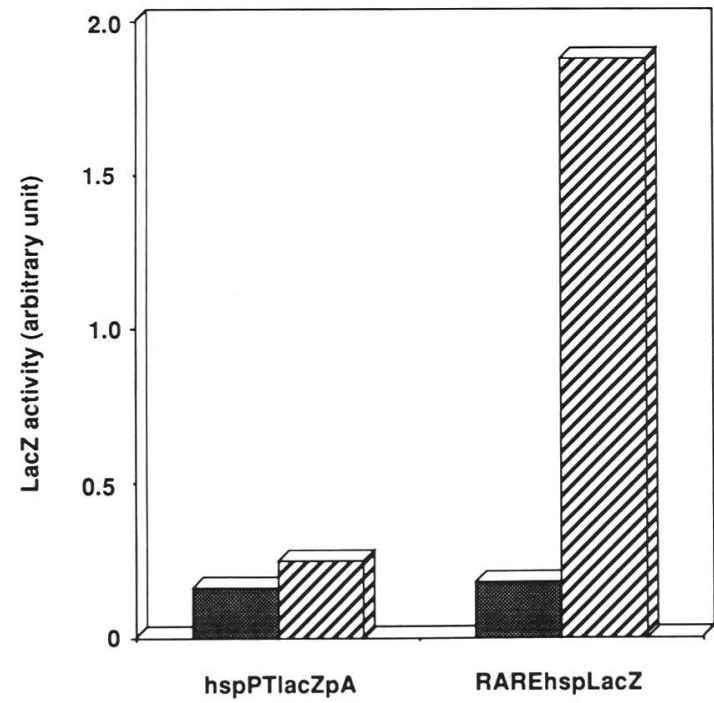

Figure 1. Structure of the RAREhsplacZ transgene and its responsiveness to RA in vitro. (A) Nucleotide sequence of the oligonucleotide containing the RARE derived from the RAR $\beta$ gene. A HindIII site not present in the RAR $\beta$ gene was added to allow cloning of the oligonuclotide into reporter plasmids. The arrows indicate the direct repeats essential for RA inducibility. $(B)$ Organization of the RA-responsive and control transgene. Three copies of the oligonucleotide encoding the RARE were inserted upstream of the $h s p 68$ promoter to give the reporter plasmid RAREhsplacZ. The three large arrows show the orientation of each RARE; the small arrow indicates the site of initiation of transcription within the hsp 68 promoter. $(C)$ Induction of $\beta$-galactosidase activity in F9 teratocarcinoma cells. F9 cells were transfected with either the nonresponsive ( $p h s p P T$ lacZpA) or RA-responsive ( $p R A R E h s p l a c Z$ ) reporter gene and cultured for $24 \mathrm{hr}$ in the presence (hatched bar) or absence (shaded bar) of $100 \mathrm{~nm}$ RA. The results are expressed in arbitrary units of $\beta$-galactosidase enzyme normalized for transfection efficiency, with luciferase activity as an internal control.

receptor gene and treatment with $T_{3}$ did not activate the construct (not shown).

\section{Generation of transgenic mice}

Injection of the RAREhsplacZ construct into the fertilized eggs of outbred CD 1 mice resulted in 69 offspring, of which 9 were transgenic by Southern blot analysis (not shown). Copy number varied considerably from an estimated 10-50 copies. There was no obvious correlation between copy number and expression. A preliminary test for transgene expression was performed by staining 10.5-day fetuses produced by mating five transgenic males to CDl females. Litters from one male showed no evidence of lacZ expression, whereas half of the fetuses from another male showed very weak blue staining throughout the embryo (not shown) but no evidence for a specific pattern. The remaining three males produced litters in which the expected $50 \%$ showed essentially identical and very specific patterns of expression. Fetuses derived from $\mathrm{Tg} 12$ showed the strongest staining, with blue color being apparent within half an hour of immersing in substrate, and so the majority of the analysis of expression patterns was performed on litters sired by mouse $\mathrm{Tg} 12$ or his transgenic male offspring. However, expression patterns were confirmed at all stages of development in the offspring of $\operatorname{Tg} 63$ and $\operatorname{Tg} 65$ as well. Unless noted otherwise, expression was identical in all three lines.

\section{Embryonic expression of RAREhsplacZ}

The earliest stage at which any expression of the transgene could be observed was the 3.5-day blastocyst, where small dots of blue staining were observed sporadically in both inner cell mass (ICM) and trophectoderm (not shown). The significance of this expression is not clear, because less than the expected $50 \%$ of blastocysts showed any staining at all. After implantation, no expression was observed in 6.5- and early 7.5-day, primitive-streak-stage embryos. Expression was not detected until the mesodermal layer was complete and the head folds were formed, demarcating the neural plate. At this stage of development, strong expression was observed in the posterior half of the embryo (Fig. 2a). Expression occurred throughout the length of the primitive streak and filled the entire posterior domain of the embryo. Upon the sectioning of these embryos, blue staining was observed in all three germ layers in the posterior domain (Fig. 4a, below). The anterior boundary of expression corresponded to the anterior end of the primitive streak (Hensen's node equivalent) in the midline and the boundary of the neural plate laterally. There was no obvious posterior-anterior gradient of staining, although there was some mosaicism in expression especially in the mesoderm layer.

Embryos were dissected at intervals during the eighth day of pregnancy to determine the exact time and manner of onset of expression. Four litters were examined before noon and none showed any detectable lacZ expression. These embryos were at advanced primitive streak stages but had no detectable head folds. By 5 p.m. $50 \%$ of all four litters examined showed the full pattern of lac $Z$ expression, and all had head folds. Three litters examined in the intervening period contained $<50 \%$ expressing embryos, but only two embryos showed less than full staining. In these embryos the head folds were 

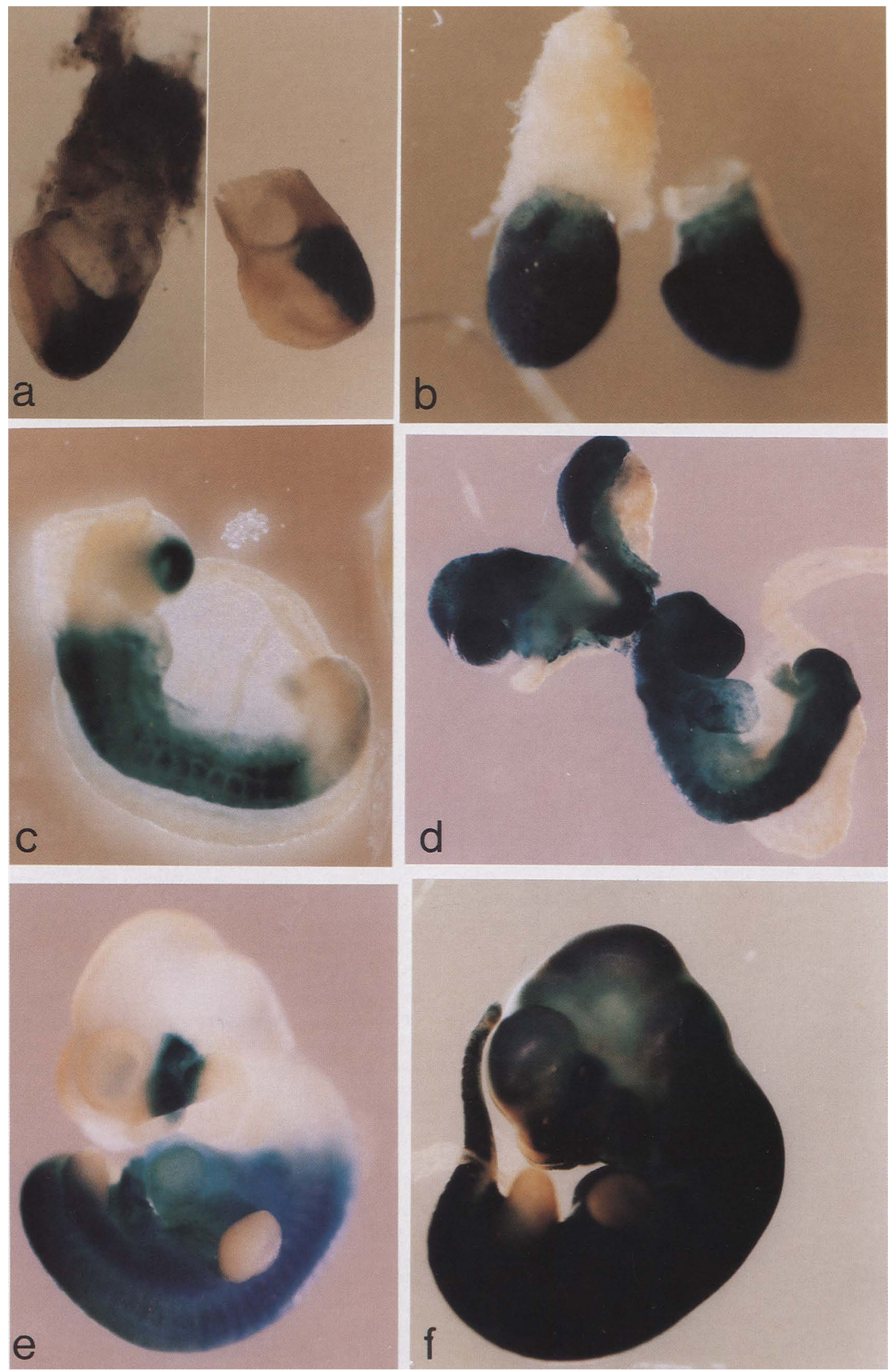

Figure 2. (See facing page for legend.) 
just becoming apparent, and expression of the transgene was still very faint. However, even at this stage, no evidence for a gradient of expression could be found; patchy expression was observed throughout the posterior domain. This indicated that there was a very rapid onset of transgene expression in the late gastrulating embryo, coincident with formation of the neural plate.

During the next day of development, as somite formation and neural tube closure began, blue staining continued to show a sharp boundary at the anterior end of the embryo, caudal to the preotic sulcus (Fig. 3a). At the posterior end of the embryo, staining appeared to be receding from the area of the primitive streak and open posterior neuropore. By the 8- to 10-somite stage the posterior boundary of expression had stabilized, producing a sharp decline in lac $Z$ activity across the entire embryo behind the last formed somite (Fig. 2c). Expression was then completely absent from the regressing primitive streak and the posterior neuropore. Expression was observed in all tissues in the middle of the embryo, including the developing heart, only to cease abruptly anterior to the first somite but posterior to the hindbrain and otic vesicle (Figs. $2 \mathrm{c}$ and $4 \mathrm{c}$ ). Within the prospective head region of the embryo, additional expression was only observed in the area of the optic eminence. Sections of this region revealed expression in the underlying neural tube that will form the optic lobes, as well as in overlying head mesenchyme and ectoderm (Fig 4c).

By 10.5 days, expression of the RAREhsplacZ transgene showed more tissue-specific variation. Externally, expression still defined a domain of the body stretching from the beginning of the spinal cord to the base of the tail (Fig. 2); but sectioning revealed that although staining was still apparent in the skin and somites, strong expression was confined to the spinal cord and endoderm layer of the developing gut. Staining was apparent throughout the dorsal-ventral axis of the spinal cord, although there was less stain ventrally. The developing ventral motor axons also stained blue, but the dorsal root ganglia were negative. Other negative tissues included the liver and the developing limb buds except for mesenchyme at the very base, apparent only after sectioning (Fig. 5a). In the head region there was a striking stripe of expression surrounding the developing eye and demarcating the nasolachrimal groove (Fig. 2e). Sectioning revealed that this staining was restricted to the ectodermal layers and subdivided the surface of the maxilla into rostral and caudal halves (not shown). Expression was also observed in the developing eye itself, in both presumptive lens and retina. Expression of the transgene was ob- served in the telencephalic vesicles of the brain in the $\mathrm{Tg} 12$ line (Fig. 3b). Similar staining was observed only weakly after staining of offspring of Tg63 and Tg65 (Fig. 2e). Presumably, the enhanced staining observed in this region with $\mathrm{Tg} 12$ was the result of interaction with some other controlling elements at the site of integration in this particular line.

Expression at later stages was not examined in detail, as this expression is more likely to reflect the role of RA in specific tissue differentiation than in basic establishment of the body plan. However, examination of intact (Fig. 3b) and dissected stained embryos at 11.5-12.5 days revealed more restricted $l a c Z$ expression. In the head region, expression remained essentially similar, with the addition of expression in a small region of ectoderm between the mandible and maxilla, part of the developing nasal placode and the developing ear (Fig. 3b). Internally, expression within the spinal cord became more clearly restricted to the dorsal region but the dorsal root ganglia remained negative (not shown). Expression was still observed in the skin and underlying somite-derived tissues. In internal organs, strong expression was confined to the cardiac portion of the stomach and the developing metanephric kidneys (not shown). By 13.5-14.5 days little staining was apparent externally after staining whole embryos (Fig. 3c). In the head region there was still staining associated with the eye and the remnants of the nasolacrimal groove. The developing olfactory epithelium stained blue, and there was also some staining in the jaw region. The strongest staining at this stage of development was observed in the developing limbs, where the regions of cell death involved in generating digits were clearly defined by blue staining. The only other staining observed at this stage was in the extraperitoneal gut region at the base of the umbilical cord. The apparent absence of significant internal staining in whole embryos stained at these stages probably does not reflect absence of expression but, rather, failure of the stain to penetrate all tissues.

\section{Altered pattern of expression of RAREhsplacZ after maternal treatment with $R A$}

Pregnant females were treated with teratogenic doses of RA at four stages of pregnancy: late 6.5 , early $7.5,8.5$, and 10.5 days. Treatment at 6.5 or early 7.5 days, when control embryos showed no staining, resulted in activation of the lac $Z$ construct in the entire embryonic region of the egg cylinder (not shown). When treated on the morning of day 7.5 and dissected and stained $6 \mathrm{hr}$ later,

Figure 2. Transgenic embryos stained with X-gal with or without pretreatment with RA. $(a, c, e)$ No RA treatment; $\{b, d, f)$ RA treated. $(a, b)$ Early 7.5-day head-fold-stage embryos showing blue staining in the posterior region of the embryo only in untreated embryos and staining throughout the entire embryonic region and the lining of the extraembryonic region in treated embryos. In $a$, the embryo at left is from $\mathrm{Tg} 12$ and that at right is from $\mathrm{Tg} 63$. All treated embryos are from $\mathrm{Tg} 12$. (c,d) Late 8.5-day embryos ( 9-10 somites) showing staining in the mid-region of the embryos and in the optic eminence in untreated embryos and uniform staining throughout the embryos after RA treatment. $(e, f)$ These are 10.5-day embryos. Tg63 (untreated) embryos showed absence of staining anterior to the brain-spinal cord boundary, except for a band spanning the nasolachrimal groove, and no staining in the limb buds or tail region (not visible). Treated embryos ( $\operatorname{Tg} 12)$ showed extensive staining throughout the head region and the tail and some additional staining in the limb buds. 
Figure 3. Untreated embryos of other developmental stages stained with X-gal. (a) Two Tgl2 embryos at 1-somite (left) and 3-somite (right) stages, showing progressive reduction of posterior staining as the posterior neuropore develops and the primitive streak recedes. $(b)$ Four 11.5-day embryos from mating a $\mathrm{Tg} 12 /$ - male with a wild-type female; three are transgenic and one is a nontransgenic sibling as control for endogenous staining. The pattern is very similar to that seen at 10.5 days, with the addition of a patch of staining at the junction between the maxilla and the mandible. Note the staining in the telencephalic vesicles, which are only clearly seen in the Tg12 line. Also note that the diffuse blue stain visible in the lumen of the hindbrain is due to diffusion of the product of the staining reaction and not cellular staining in this region. (c) A 14.5-day Tg63 embryo showing only light staining over most of the body surface. Stronger staining is still found in the region of the eye, the whisker pads, and the jaw. New staining is apparent in the herniated gut and in the interdigit regions of the limbs.
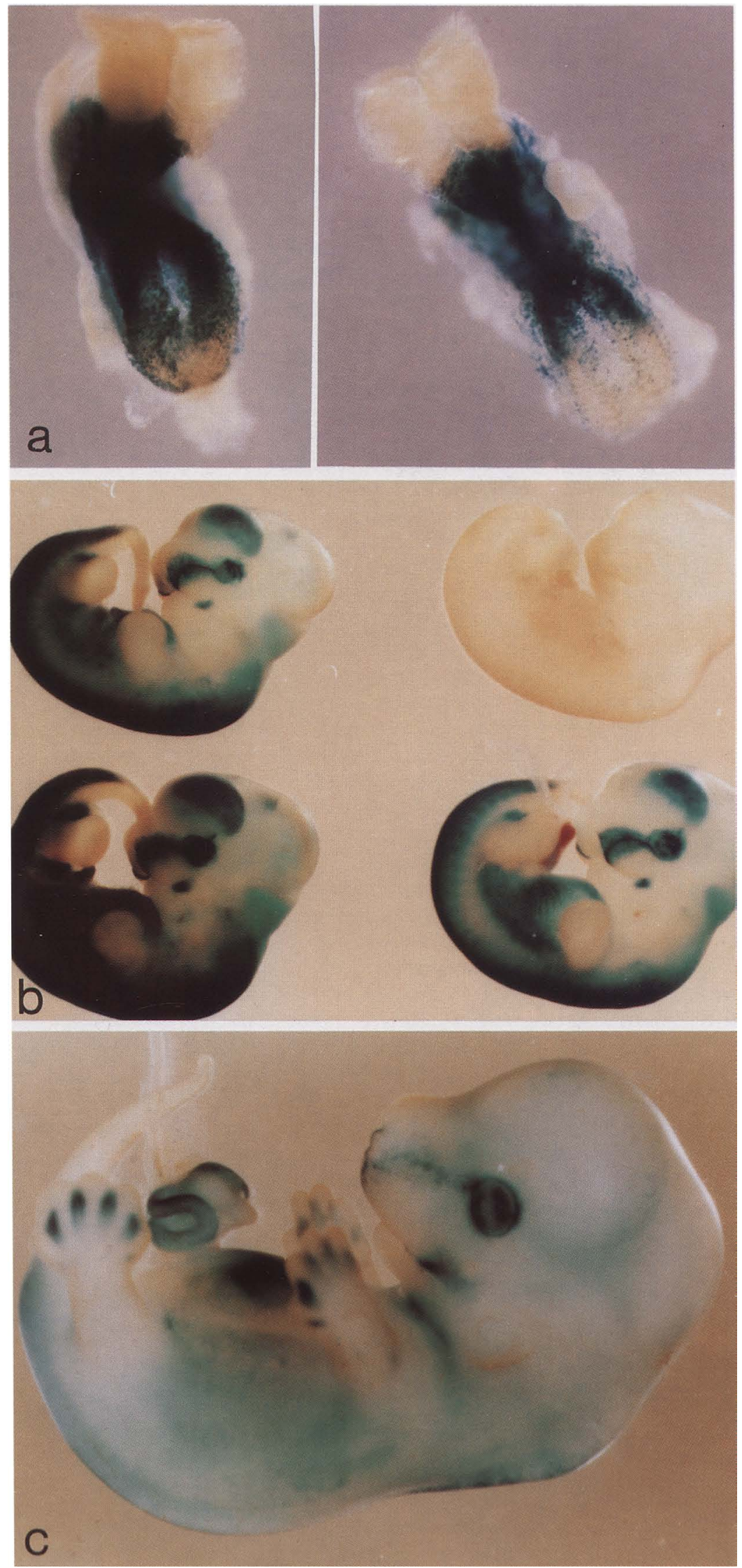


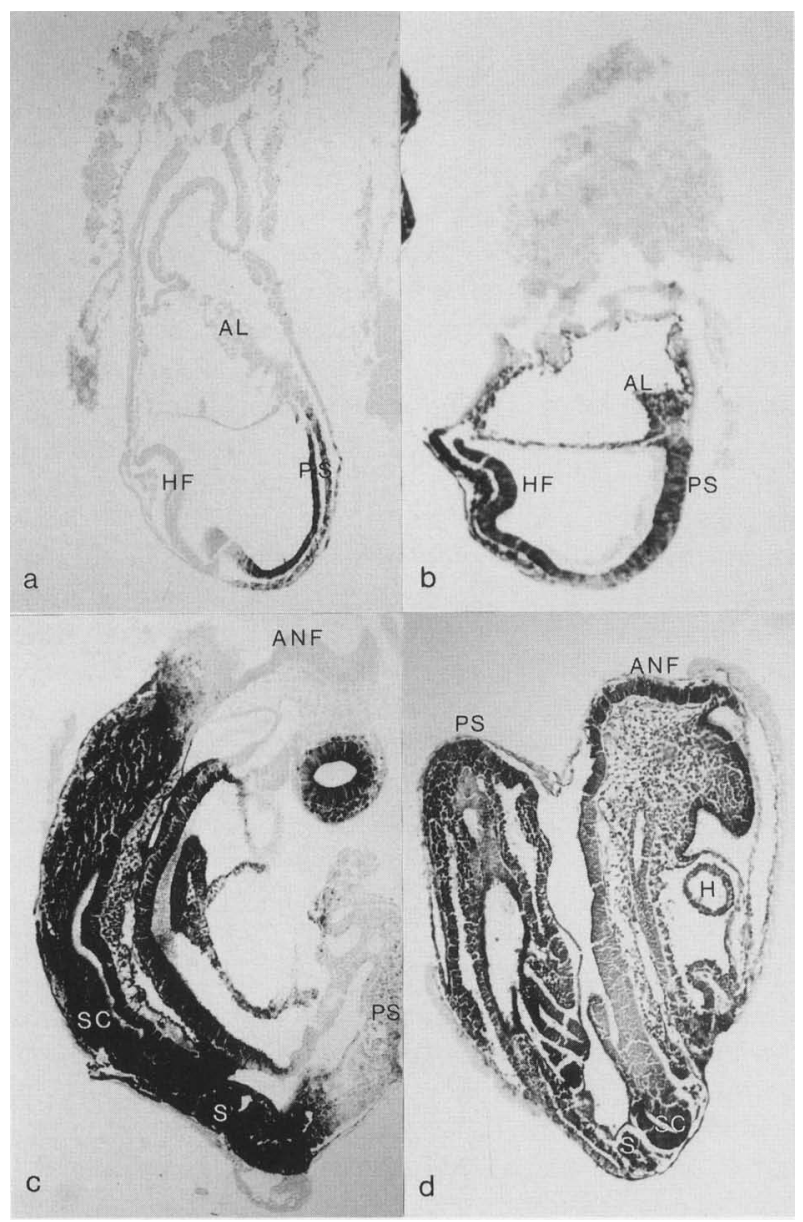

Figure 4. Approximately mid-sagittal sections of 7.5- and 8.5day untreated and RA-treated embryos. All sections are from Tg12 transgenic embryos. (a) Untreated 7.5-day embryo showing intensive staining in all three germ layers at the posterior end of the embryo but no staining in the head folds. (b) A similar stage embryo after $6 \mathrm{hr}$ of RA treatment showing blue stain throughout the embryo and also in the extraembryonic mesoderm and allantois. (c) These 8.5-day embryos show transgene expression in all tissues of the mid-region, including spinal cord and somites but little staining in the posterior end of the embryo. In the prospective head region staining is observed in the developing optic lobes and surrounding mesenchyme. $(d)$ Treated embryo at the same stage shows staining along the entire length of the body axis. (HF) Head folds; (PS) primitive streak; (AL) allantois; (SC) spinal cord; (ANF) anterior neural folds; (S) somites. Bar, $0.5 \mathrm{~mm}$.

control embryos showed the expected posterior-restricted domain of staining but treated embryos showed no distinction between anterior and posterior regions (Fig. 2b). Staining was intense in all germ layers including the developing neural plate (Fig. $4 \mathrm{~b}$ ). In the extraembryonic region, extraembryonic mesoderm but not endoderm showed blue staining. Treatment early on day 8.5 also led to activation of the $l a c Z$ construct in all regions of the developing embryo, filling both the anterior and posterior domains that were unstained in untreated embryos (Figs. $2 \mathrm{~d}$ and $4 \mathrm{~d}$ ).
Treatment at 10.5 days also appeared to have a dramatic effect on $l a c Z$ expression, with whole-mount staining revealing stronger and more extensive staining than in untreated controls (Fig. 2f). Expression was observed along the full length of the body axis, including the tail, and was also apparent in large regions of the head not stained in controls. Both the maxilla and mandible showed staining over their entire surface, and staining was apparent for the first time in the limb buds, with expression strongest proximally and weakest at the distal tip.

Because the RAREhsplacZ construct contained some elements of the mouse heat-inducible hsp 68 promoter, it was important to demonstrate that the effects of RA treatment were mediated through the RARE and not through induction of the stress response. In vitro transfection had already demonstrated that the hsplacZ construct lacking the RARE showed no activation upon RA treatment. To confirm that the same was true in vivo, we mated female mice with males of two different lines carrying hsplac $Z$ constructs that lacked the RARE but in which the lac $Z$ gene had been activated in specific de-

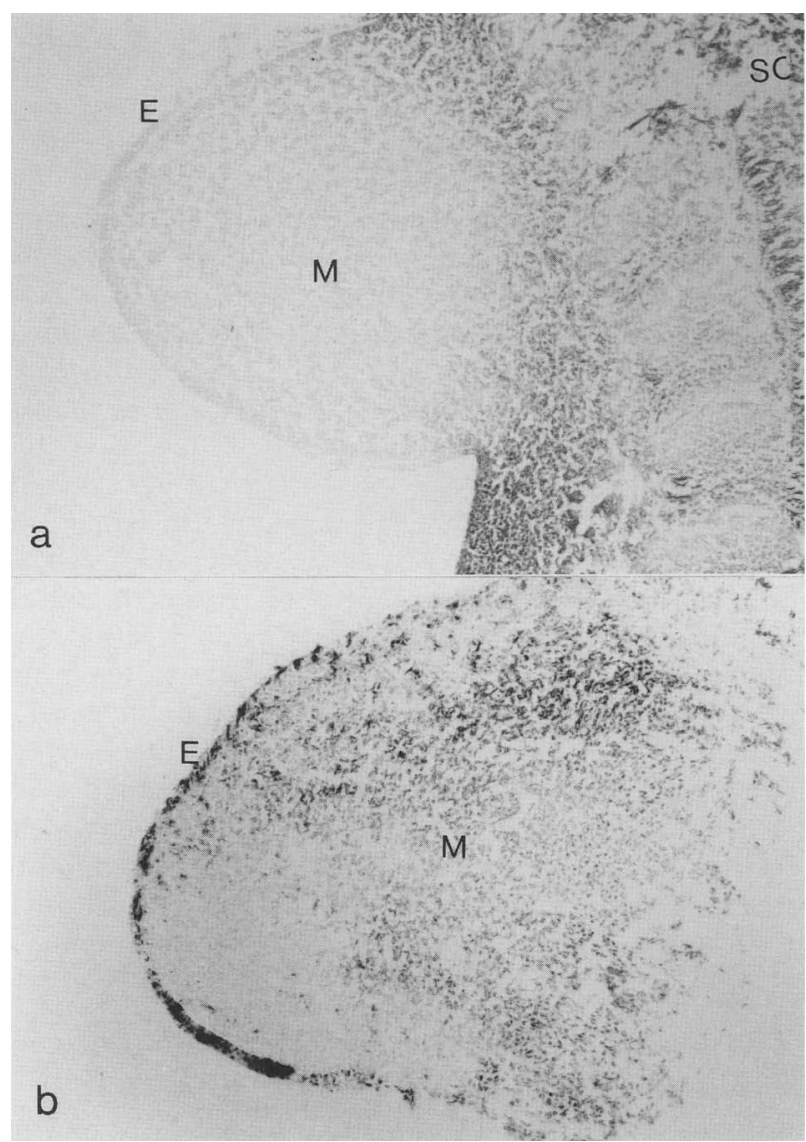

Figure 5. Hind limb buds from untreated and RA-treated Tgl2 embryos. (a) Untreated limb bud region showing complete absence of staining in the ectoderm and mesenchyme of the limb bud. (b) Treated limb bud showing patchy expression in both ectoderm and mesenchyme. (SC) Spinal cord; (E) limb bud ectoderm; (M) limb bud mesenchyme. Bar, $0.2 \mathrm{~mm}$. 
velopmental patterns by elements at its site of integration. Treatment of 8.5-day fetuses of either strain with RA did not result in any activation of lacZ over the intrinsic staining pattern (not shown).

\section{Discussion}

The RARE defined from in vitro studies of the regulation of the RAR $\beta$ gene caused very specific and reproducible patterns of activation of a minimal promoter-lac $Z$ construct during the process of establishing the basic body plan in transgenic mouse embryos. This suggests that the morphogenetic effects of RA are, at least in part, mediated by the direct interaction between the RARs and their cognate response elements and consequent transcriptional activation of developmentally regulated genes. lac $Z$ expression was activated very rapidly around the time of neural plate formation and defined the posterior domain of the embryo. This domain encompassed all three germ layers and the primitive streak itself, and in the midline its anterior boundary coincided with the position of the mammalian equivalent of Hensen's node. During the next 2 days of development, the domain of expression shifted so that by the 10-somite stage, the anterior end of the primitive streak, which began by marking the anterior limit of expression, became associated with the posterior limit of expression. This posterior to anterior shift occurred concomitantly with the forward progression of the notochord, presomitic mesoderm, and somites from the anterior end of the primitive streak. By 9.5 days a second domain of expression was established in the head region, around the developing optic region, which later extended down the nasolachrimal groove and delineated specific anterior and posterior boundaries in the ectoderm of the nasal region and the maxilla.

The significance of these expression patterns for understanding developmental mechanisms can be considered at two levels. Regardless of its mode of activation, the axial, but not tissue-specific, restriction of expression of this artificial gene construct, combined with its very distinct anterior and posterior boundaries, lends further support to the general notion that there is genetic control of the A/P pattern along the axis of the developing mouse embryo (Graham et al. 1989; Frohman et al. 1990; Kessel and Gruss 1990). However, if it could be shown that expression of the construct reflected specific sites of action of RA, the results would implicate RA itself in this $\mathrm{A} / \mathrm{P}$ patterning process.

\section{Correlation between sites of transgene expression and sites of RA action}

To what extent do the domains of expression of the transgene represent the specific and complete domains of action of RA in the embryo? Proof that the expression of the transgene was induced specifically by RA in the embryo is difficult to obtain. Control experiments showed that the hsplacz construct alone was not activated in vitro or during development either in the pres- ence or absence of exogenous RA, proving that expression of the transgene depended entirely on the presence of the RARE. In vitro studies have shown that no other known ligand-receptor complex will stimulate transcription via the RARE (de Thé et al. 1990; Sucov et al. $1990)$. In the intact embryo, the RARE construct could be exposed to unknown ligand-receptor complexes that might also act through the RARE. The possible existence of such complexes is suggested by the discovery that other retinoids and related retinoid receptors, the RXRs (Mangelsdorf et al. 1990), occur in developing systems (Thaller and Eichele 1990). However, expression of $\mathrm{RXR} \alpha$ in the chick embryo is confined to the peripheral nervous system and the liver (Rowe et al. 1991)-tissues where the RARElacZ transgene is not expressed. Furthermore, exogenous treatment with RA activated novel domains of expression of the transgene, showing that RA can activate gene expression via the RARE in vivo and suggesting by inference that the expression patterns observed in the untreated embryo were due, in large part, to the action of RA.

Assuming that the expression of the transgene was specifically induced by RA, did the observed expression patterns provide a complete reflection of the sites of action of RA in the embryo? By placing the RARE upstream of a promoter that showed no tissue-specific regulation, we hoped to provide a clearer picture of the sites of transcriptional action of RA than was provided by examining the expression of RARs themselves. At the head-fold stage, the RAREhsplacZ transgene showed a more spatially restricted pattern of expression and a more precise time of onset of expression than reported for any of the RARs (Ruberte et al. 1991). At presomitic stages of development, only RAR $\beta$ showed any clear spatially restricted expression, but no precise anterior boundary of expression transcending germ layers was observed (Ruberte et al. 1991). Interestingly enough, the pattern of expression of RAR $\beta$ in the head-fold stage chick embryo seems to resemble the transgene expression more closely (Smith and Eichele 1991), suggesting that the chick RAR $\beta$ may be more dependent on RA for its expression than the same receptor in the mouse.

At early somite stages the anterior and posterior boundaries of expression of the RAREhsplacZ transgene resembled the boundaries of expression of the RAR $\beta$ gene more closely than the other receptors did. However, within this domain, the RAR $\beta$ gene showed more restricted expression than did the transgene. Most notably, RAR $\beta$ transcripts were absent from the somites, whereas the transgene was expressed in all tissues of the midregion of the embryo. This finding suggests that there may be elements associated with the RAR $\beta$ gene promoter that can prevent its induction by RA in certain tissues. It also indicates that, in vivo, the RARE element can bind and be activated by ligand-receptor complexes other than those involving the RAR $\beta$. Precise alignment of the anterior and posterior boundaries of expression of the $\beta$ receptor and the transgene is difficult to achieve from comparison of in situ hybridization and lacZ staining. However, it appears that the posterior boundaries 
may be identical, both excluding the open caudal neuropore where RAR $y$ is known to be expressed (Ruberte et al. 1991).

Later in development, from 11.5 days on, the pattern of expression of the transgene became more complex and tissue restricted, and closely resembled the reported expression of the RAR $\beta$ gene (Dollé et al. 1990). Perhaps the most obvious similarity to RAR $\beta$ expression was the presence of blue staining in the areas of cell death in the interdigits of the developing limbs. This pattern is typical of the $\beta$ receptor but not the $\alpha$ or $\gamma$ receptors, which show more widespread expression in the limb.

Thus, the restricted domains of expression of the transgene, particularly at early stages, cannot be explained simply by restricted receptor distribution. However, they do not prove that RA itself is entirely restricted to the domains observed. Regulation of the RA response is complex and involves interaction of RA levels, binding protein, and receptor distribution, as well as interactions with accessory transcription factors. This makes it possible that the same RARE in front of another basal promoter might result in slightly different patterns of activation. It is also possible that different RAREs may respond preferentially to different RAR complexes. Further transgenic manipulations may help dissect these complexities.

\section{$R A$ and $A / P$ patterning}

The fact that the addition of the RARE alone is sufficient to impose specific anterior and posterior boundaries of expression on a supposedly "neutral" gene construct at the presomite and early somite stages of development, and that these boundaries can be obliterated by increasing RA concentration, strongly suggests that RA may play a role in $\mathrm{A} / \mathrm{P}$ patterning in the mouse embryo. Although we did not observe any evidence for a gradient of RA responsiveness along the body axis, this may simply reflect the threshold responsiveness of the particular construct used and need not eliminate the possibility of graded action of RA. One could envisage that RA response elements could combine with other elements upstream of different genes to generate graded responses to RA along the body axis.

Little is known about the mechanisms of $\mathrm{A} / \mathrm{P}$ patterning in the postimplantation mouse embryo, although the expression patterns of a number of different genes suggest that regional specialization occurs within the neuroectoderm and underlying mesoderm at least by early somite stages. Experimental evidence from Xenopus suggests that the dorsal mesoderm acquires $\mathrm{A} / \mathrm{P}$ polarity during gastrulation and subsequently induces regional differences along the $\mathrm{A} / \mathrm{P}$ axis in the developing neural epithelium (for review, see Nieuwkoop et al. 1985). Thus, for RA to be involved in the initial $\mathrm{A} / \mathrm{P}$ regionalization, one would predict that RA responsiveness should be first acquired in mesoderm. However, the expression boundary of the RAREhsplacZ transgene was established simultaneously across all three germ layers shortly after the establishment of the neural plate, sug- gesting that the positional signal provided by RA may be independently received and interpreted by ectoderm and mesoderm. In support of this finding, it has recently been shown that exogenous RA treatment can act directly on both ectoderm and mesoderm in Xenopus (Sive et al. 1990; Ruiz i Altaba and Jessell 1991). RA can suppress anterior ectoderm differentiation in previously induced isolated dorsal ectoderm (Sive et al. 1990) and suppresses anterior dorsal mesoderm in induced animal caps (Ruiz i Altaba and Jessell 1991). Reduction of anterior structures, both ectodermal and mesodermal, occurs when intact Xenopus embryos are treated with RA (Durston et al. 1989; Sive et al. 1990). Whether this reduction involves a concomitant increase in posterior structures is not clear. It is possible that the main role of RA at this stage of development is to suppress anterior differentiation across all germ layers, rather than actively induce posteriorization, as suggested previously (Durston et al. 1989|.

Our results do not provide any direct support for a role for RA in A/P patterning in the limb bud. Little expression of the construct was observed in the developing limb buds, suggesting that if RA is transcriptionally active in limb development it functions via other response elements. Recent evidence suggests that RA may not act directly in a morphogenetic gradient across the limb bud but that exogenous RA may act to induce a new zone of polarizing activity that establishes the graded response by other means (Noji et al. 1991; Wanek et al. 1991). Our failure to detect gradients or thresholds of activity in the limb bud is consistent with this possibility.

\section{Teratogenic action of $R A$}

It is interesting to note that the areas of endogenous RA action defined here by expression of the RARE transgene are, by and large, not the areas where exogenous RA treatment during pregnancy has been reported to show a teratogenic effect. This suggests that teratogenesis by RA may be due to ectopic activation of RA-responsive genes in the wrong place and may not necessarily indicate the normal domains of action of RA. When compared with published in situ and protein localization studies on CRABP I (Eriksson et al. 1987; Perez-Castro et al. 1989; Dollé et al. 1990; Vaessen et al. 1990), it is clear that the pattern of expression of the transgene and CRABP are largely reciprocal, supporting the notion that CRABP acts to sequester RA, and that teratogenic action results from saturation of the binding protein. However, it will be important to determine the developmental distribution of CRABP II, which has recently been cloned and shown to be expressed during embryogenesis (Giguère et al. 1990b), before drawing any firm conclusions about the interactions of RA, CRABPs, and the receptors.

It is clear that no one piece of evidence alone can prove that RA acts as an endogenous morphogen in vertebrate development. However, the cumulative data on the effects of exogenous retinoids, measurements of endogenous retinoid levels, and the spatially restricted distri- 
butions of the receptors and accessory proteins required for RA action strongly support such roles. The results described here do not provide any support for a role for RA in primary mesoderm induction or migration or in the initial stages of neural induction, but they do support a role for RA in establishing spatial domains along the primary body axis early after gastrulation. Further understanding of this role will require a generation of mutations in the various components of the RA response system by targeted mutagenesis (Capecchi 1989; Rossant and Joyner 1989). The transgenic mice described here will facilitate study of the effects of such mutations on the RA response in vivo.

\section{Materials and methods}

\section{Vector construction and in vitro activity}

The vector $\mathrm{pRAREhsplacZ}$ was made by inserting a DNA fragment containing three copies of the 32-bp oligonucleotide sequence (see Fig. 1A) that defines the RARE upstream of the RAR $\beta$ into the SmaI site of pGEM7zf. A KpnI fragment from phspPTlacZpA (Kothary et al. 1989) was then inserted downstream of the RARE at the KpnI site. The KpnI fragment from phspPTlacZpA contained $610 \mathrm{bp}$ upstream of the start of transcription of the mouse hsp68 gene (Perry and Moran 1987). An additional $225 \mathrm{bp}$ of sequence, including the translational start site of the hsp 68 gene, was fused in-frame with the Escherichia coli $\beta$-galactosidase gene from p1871 (Pharmacia), so as to generate a Kozak consensus sequence for efficient translation of the prokaryotic gene in eukaryotic cells. The $5^{\prime}$ sequences from the hsp68 gene contain a TATA box at position - 30, an Spl site around position -50 , a CAAT box at position -70 , and three heat shock elements around positions $-100,-190$, and -300 . Sequence analysis confirmed that the vector contained three copies of the RARE and that these were arranged in the configuration shown in Figure 1B. To compare the RA responsiveness of $\mathrm{p} R A R E h s p l a c Z$ with the control plasmid phspPTlac $Z p A$, F9 cells $\left(5 \times 10^{5} / 10-\mathrm{cm}\right.$ dish) were cotransfected with either reporter plasmid phspPTlacZpA or pRAREhsplacZ $(5 \mu \mathrm{g})$, the internal control Rous sarcoma virus-luciferase (RSV-LUC), and the carrier plasmid pGEM4 (10 $\mu \mathrm{g}$ ) by calcium phosphate coprecipitation. The following day, transfected cells were washed twice in PBS and fed with Dulbecco's modified Eagle medium containing $10 \%$ resin-charcoal-stripped calf serum with or without $100 \mathrm{~nm}$ RA. As described elsewhere /Giguére at al. 1990a), $\beta$-galactosidase, and luciferase assays were performed 24 hr after induction of the cells with RA.

\section{Transgenic mice: production and identification}

Transgenic mice were generated on an outbred CD-1 background by standard procedures (Hogan et al. 1986), and transgenic offspring were identified by hybridizing Southern blots of tail DNA with a lacZ DNA probe. Male transgenic mice were mated with CD-1 females, and fetuses were examined in midgestation for lacZ expression. Only those males that showed specific spatially regulated expression were retained for further breeding and analysis.

\section{Expression analysis}

All analysis described here was performed on litters obtained from mating hemizygous male transgenic mice, either founders or their offspring, with outbred females. By this means, each set of embryos produced contained half-transgenic and half-wildtype genotypes, thus providing internal controls to ensure that none of the staining observed was due to endogenous mammalian $\beta$-galactosidase.

Blastocysts were obtained by flushing the uteri of pregnant females on the fourth day of pregnancy, whereas all postimplantation stages were obtained by dissecting conceptuses directly from the decidua. All dissections were performed in PBS to avoid any potential outside source of retinoids. Embryos were fixed briefly in $0.2 \%$ gIutaraldehyde in PBS at $4^{\circ} \mathrm{C}$ for $15 \mathrm{~min}$, rinsed, and then stained in X-gal (Gossler et al. 1989) at $37^{\circ} \mathrm{C}$. Depending on the line of mice and stage of development, blue staining was apparent between $30 \mathrm{~min}$ and $4 \mathrm{hr}$ after initiation of staining. Embryos were photographed in a Wild Makroskop and then stained overnight to ensure complete penetration of stain, before postfixing in Omnifix (Fisher), processing, and embedding in paraffin wax. Sections were cut at $7 \mu \mathrm{m}$ and mounted on glass slides. Counterstaining was performed with eosin. To confirm that the expression patterns observed were not compromised by incomplete stain penetration, some 10.5-day embryos were frozen rapidly in O.C.T. medium (Tissue-Tek), and cryostat sections were cut at $10 \mu \mathrm{m}$. Sections were then fixed briefly in $4 \%$ paraformaldehyde in PBS, rinsed, and stained for $\beta$-galactosidase activity. Patterns of internal tissue expression were similar in paraffin and cryostat sections. This comparison has not been made at later stages, but other studies (J. Rossant, unpubl.) indicate that incomplete stain penetration in whole embryos may become a concern in later stages.

In some experiments, pregnant females were treated with RA at various times before embryo dissection. RA was administered at a dose of $20 \mathrm{mg} / \mathrm{kg}$ by gastric lavage. A stock solution of $25 \mathrm{mg} / \mathrm{ml}$ of RA in dimethylsulfoxide was dissolved just before use in corn oil so that a $0.2-\mathrm{ml}$ dose of oil contained the requisite amount of RA. Control mice received corn oil alone.

\section{Acknowledgments}

We thank M. Breitman, A. Joyner, E. Linney, and C. Moens for useful discussion. This research was supported by grants from the National Cancer Institute of Canada (NCI) (V.G., J.R), the Medical Research Council (MRC) of Canada (V.G., J.R), and Bristol-Myers-Squibb Ltd (J.R.). V.G. is a MRC Scholar, J.R. is a Terry Fox Cancer Research Scientist of the NCI, and M.S. holds an MRC Studentship.

The publication costs of this article were defrayed in part by payment of page charges. This article must therefore be hereby marked "advertisement" in accordance with 18 USC section 1734 solely to indicate this fact.

\section{References}

Benbrook, D., E. Leinhardt, and M. Pfahl. 1988. A new retinoic acid receptor identified from a hepatocellular carcinoma. Nature 333: 669-672.

Brand, N., M. Petkovich, A. Krust, P. Chambon, H. de Thé, A. Marchio, P. Tiollais, and A. Dejean. 1988. Identification of a second human retinoic acid receptor. Nature 332: 850-853.

Brockes, J.P. 1989. Retinoids, homeobox genes, and limb morphogenesis. Neuron 2: 1285-1294.

Capecchi, M.R. 1989. Altering the genome by homologous recombination. Science 244: 1288-1292.

Dencker, L., E. Annerwall, C. Busch, and U. Eriksson. 1990. Localization of specific retinoid-binding sites and expression of cellular retinoic acid-binding protein (CRABP) in the early mouse embryo. Development 110: 343-352. 
de Thé, H., M. del Mar Vivanco-Ruiz, P. Tiollais, H. Stunnenberg, and A. Dejean. 1990. Identification of a retinoic acid responsive element in the retinoic acid receptor $\beta$ gene. $\mathrm{Na}$ ture 343: 177-180.

Dollé, P., E. Ruberte, P. Kastner, M. Petkovich, C.M. Toner, L. Gudas, and P. Chambon. 1989. Differential expression of the genes encoding the retinoic acid receptors $\alpha, \beta, \gamma$ and CRABP in the developing limbs of the mouse. Nature 342: 702-705.

Dollé, P., E. Ruberte, P. Leroy, G. Morriss-Kay, and P. Chambon. 1990. Retinoic acid receptors and cellular retinoid binding proteins. I. A systematic study of their differential pattern of transcription during mouse organogenesis. Development 110: 1133-1151.

Durston, A.-J., J.P.M. Timmermans, W.J. Hage, H.F.J. Hendriks, N.J. de Vries, M. Heideveld, and P.D. Nieuwkoop. 1989. Retinoic acid causes an anteroposterior transformation in the developing central nervous system. Nature 340: 140-144.

Eichele, G. 1989. Retinoids and vertebrate limb pattern formation. Trends Genet. 5: 246-251.

Eriksson, U., E. Hannson, H. Nordlinger, C. Busch, J. Sundelin, and P.A. Peterson. 1987. Quantitation and tissue localization of cellular retinoic acid-binding protein. J. Cell Physiol. 133: 482-490.

Evans, R.M. 1988. The steroid and thyroid hormone receptor superfamily. Science 240: 889-895.

Frohman, M.A., M. Boyle, and G.R. Martin. 1990. Isolation of the mouse Hox-2.9 gene; analysis of embryonic expression suggests that positional information along the anterior-posterior axis is specified by mesoderm. Development 110: $589-607$.

Geelen, I.A.G. 1979. Hypervitaminosis A induced teratogenesis. CRC Crit. Rev. Toxicol. 6: 351-375.

Giguère, V., E.S. Ong, P. Segui, and R.M. Evans. 1987. Identification of a receptor for the morphogen retinoic acid. Nature 330: 624-629.

Giguère, V., M. Shago, R. Zirngibl, P. Tate, J. Rossant, and S. Varmuza. 1990a. Identification of a novel isoform of the retinoic acid receptor $\gamma$ expressed in the mouse embryo. Mol. Cell. Biol. 10: 2335-2340.

Giguère, V., S. Lyn, P. Yip, C.-H. Siu, and S. Amin. 1990b. Molecular cloning of cDNA encoding a second cellular retinoic acid-binding protein. Proc. Natl. Acad. Sci. 87: 6233-6237.

Glass, C.K, S.M. Lipkin, O.V. Devary, and M.G. Rosenfeld. 1989. Positive and negative regulation of gene transcription by a retinoic acid-thyroid receptor heterodimer. Cell 59: $697-708$.

Glass, C.M., O.V. Devary, and M.G. Rosenfeld. 1990. Multiple cell type-specific proteins differentially regulate target sequence recognition by the retinoic acid receptor. Cell 63: 729-738.

Gossler, A., A. Joyner, J. Rossant, and W.C. Skarnes. 1989. Mouse embryonic stem cells and reporter constructs to detect developmentally regulated genes. Science 244: 463-465.

Graham, A., N. Papalopulu, and R. Krumlauf. 1989. The murine and Drosophila homeobox gene complexes have common features of organization and expression. Cell 57: 367-378.

Green, S. and P. Chambon. 1988. Nuclear receptors enhance our understanding of transcription regulation. Trends Genet. 4: 309-314.

Hemmati-Brivanlou, A., R.M. Stewart, and R.M. Harland. 1989. Region-specific neural induction of an engrailed protein by anterior notochord in Xenopus. Science 250: 800-803.

Hirano, S., S. Fuse, and G.S. Sohal. 1991. The effect of the floor plate on pattern and polarity in the developing central nervous system. Science 251: 310-313.

Hogan, B., F. Costantini, and E. Lacy. 1986. Manipulating the mouse embryo. A laboratory manual. Cold Spring Harbor Laboratory; Cold Spring Harbor, New York.

Hornbruch, A. and L. Wolpert. 1986. Positional signalling by Hensen's node when grafted to the chick limb bud. I. Embryol. Exp. Morphol. 914: 257-265.

Ishikawa, T., K Umesono, D.J. Mangelsdorf, H. Aburatani, B.Z. Stanger, Y. Shibasaki, M. Imawari, R.M. Evans, and F. Takaku. 1990. A functional retinoic acid receptor encoded by a gene on human chromosome 12. Mol. Endocrinol. 4: 837-844.

Kastner, P., A. Krust, C. Mendelsohn, J.M. Gamier, A. Zelent, P. Leroy, A. Staub, and P. Chambon. 1990. Murine isoforms of retinoic acid receptor- $\gamma$ with specific patterns of expression. Proc. Natl. Acad. Sci. 87: 2700-2704.

Kessel, M. and P. Gruss. 1990. Murine developmental control genes. Science 249: 374-379.

Kochhar, D.M. 1985. Skeletal morphogenesis: Comparative effects of a mutant gene and a teratogen. In Developmental mechanisms: Normal and abnormal. pp. 267-281. Alan R. Liss, New York.

Kothary, R., S. Clapoff, S. Darling, M.D. Perry, L.A. Moran, and J. Rossant. 1989. Inducible expression of an hsp68-lacZ hybrid gene in transgenic mice. Development 105: 707-714.

Krust, A., P.H. Kastner, M. Petkovich, A. Zelent, and P. Chambon. 1989. A third human retinoic acid receptor, hRAR- $\gamma$. Proc. Natl. Acad. Sci. 86: 5310-5314.

Lammer, G.J., D.T. Chen, R.M. Hoar, N.D. Agnish, P.J. Benke, J.T. Braun, C.J. Curry, P.M. Fernhoff, A.W. Grix, I.T. Lott, J.M. Richard, and S.C. Sun. 1985. Retinoic acid embryopathy. N. Engl. J. Med. 313: 837-841.

Langman, J. and G.W. Welch. 1967. Excess vitamin A and development of the cerebral cortex. J. Comp. Neurol. 131: 1526.

Maden, M., D.E. Ong, D. Summerbell, and F. Chytil. 1988. Spatial distribution of cellular protein binding to retinoic acid in the chick limb bud. Nature 335: 733-735.

- $1989 \mathrm{a}$. The role of retinoid-binding proteins in the generation of pattern in the developing limb, the regenerating limb and the nervous system. Development 107(suppl.): 109-119.

Maden, M., D.E. Ong, D. Summerbell, F. Chytil, and E.A. Hirst. $1989 \mathrm{~b}$. Cellular retinoic acid-binding protein and the role of retinoic acid in the development of the chick embryo. Dev. Biol. 135: 124-132.

Maden, M., P. Hunt, U. Eriksson, A. Kuriowa, R. Krumlauf, and D. Summerbell. 1991. Retinoic acid-binding protein, rhombomeres and the neural crest. Development 111: 35-44.

Mangelsdorft, D.J., E.S. Ong, J.A. Dyck, and R.M. Evans. 1990. Nuclear receptor that identifies a novel retinoic acid response pathway. Nature 345: 224-229.

Morriss, G.M. 1972. Morphogenesis of the malformations induced in rat embryos by maternal hypervitaminosis. Am. J. Anat. 113: 241-250.

Nieuwkoop, P.D., A.G. Johnen, and B. Albers. 1985. The induction of the neural plate. In The epigenetic nature of early chordate development, pp. 150-162. University Press, Cambridge.

Noji, S., T. Nohno, E. Koyama, K. Muto, K. Ohyama, Y. Aoki, K. Tamura, K Ohsugi, H. Ide, S. Taniguchi, and T. Saito. 1991. Retinoic acid induces polarizing activity but is unlikely to be a morphogen in the chick limb bud. Nature 350: 83-86.

Osumi-Yamashita, N., S. Noii, T. Nohno, E. Koyama, H. Doi, K. Eto, and S. Taniguchi. 1990. Expression of retinoic acid receptor genes in neural crest-derived cells during mouse facial development. Science 264: 71-74.

Perez-Castro, A.V., L.E. Toth-Rogler, L. Wei, and M.C. Nguyen- 
Huu. 1989. Spatial and temporal patterns of expression of the cellular retinoic acid-binding protein and the cellular retinol-binding protein during mouse embryogenesis. Proc. Natl. Acad. Sci. 86: 8813-8817.

Perry, M.D. and L.A. Moran. 1987. Isolation of a mouse heat shock gene (hsp68) by recombinational screening. Gene 51: 227-236.

Petkovich, M., N.J. Brand, A. Krust, and P. Chambon. 1987. A human retinoic acid receptor which belongs to the family of nuclear receptors. Nature 330: 444-450.

Rossant, J. and A.L. Joyner. 1989. Towards a molecular genetic analysis of mammalian development. Trends Genet. 5: 277283.

Rowe, A., N.S.C. Eager, and P.M. Brickell. 1991. A member of the RXR nuclear receptor family is expressed in neural-crestderived cells of the developing chick peripheral nervous system. Development 111: 771-778.

Ruberte, E., P. Dollé, A. Krust, A. Zelent, G. Morriss-Kay, and P. Chambon. 1990. Specific spatial and temporal distribution of retinoic acid receptor $\gamma$ transcripts during mouse embryogenesis. Development 108: 213-222.

Ruberte, E., P. Dollé, P. Chambon, P. and G. Morriss-Kay. 1991. Retinoic acid receptors and cellular retinoic binding proteins. II. Their differential pattern of transcription during early morphogenesis in mouse embryos. Development 111: $45-60$.

Ruiz i Altaba, A. and T. Jessell. 1991. Retinoic acid modifies mesodermal patterning in early Xenopus embryos. Gene \& Dev. 5: 175-187.

Satre, M.A. and D.M. Kochhar. 1989. Elevations in the endogenous levels of the putative morphogen retinoic acid in embryonic mouse limb-buds associated with limb dysmorphogenesis. Dev. Biol. 133: 529-536.

Schüle, R.K Umesono, D.J. Mangelsdorf, J. Bolado, J.W. Pike, and R.M. Evans. 1990a. Jun-Fos and receptors for vitamins A and $D$ recognize a common response element in the human osteocalcin gene. Cell 61: 497-504.

Schüle, R., P. Rangarajan, S. Kliewer, L.J. Ransone, J. Bolado, N. Yang, I.M. Verma, and R.M. Evans. 1990b. Functional antagonism between oncoprotein c-jun and the glucocorticoid receptor. Cell 62: 1217-1226.

Sive, H.L, B.W. Draper, R.M. Harland, and H. Weintraub. 1990. Identification of a retinoic acid-sensitive period during primary axis formation in Xenopus laevis. Genes \& Dev. 4: 932-942.

Smith S.M. and G. Eichele. 1991. Temporal and regional differences in the expression pattern of distinct retinoic acid receptor- $\beta$ transcripts in the chick embryo. Development 111: $245-252$.

Sucov, H.M., K.K. Murakami, and R.M. Evans. 1990. Characterization of an autoregulated response element in the mouse retinoic acid receptor type $\beta$ gene. Proc. Natl. Acad. Sci. 87: 5392-5396.

Thaller, C. and G. Eichele. 1987. Identification and spatial distribution of retinoids in the developing chick limb bud. $\mathrm{Na}$ ture 327: 625-628.

Tickle, C., B. Alberts, L. Wolpert, and J. Lee. 1982. Local application of retinoic acid to the limb bud mimics the action of the polarizing region. Nature 296: 564-566.

Tickle, C., J. Lee, and G. Eichele. 1985. A quantitative analysis of the effect of all-trans-retinoic acid on the pattern of chick wing development. Dev. Biol. 109: 82-95.

Tuggle, C.K., J. Zakany, L. Cianetti, C. Peschle, and M.C. Nguyen-Huu. 1990. Region-specific enhancers near two mammalian homeobox genes define adjacent rostrocaudal domains in the central nervous system. Genes \& Dev.
4: 180-189.

Umesono, K, V. Giguère, C.K. Glass, M.G. Rosenfeld, and R.M. Evans. 1988. Retinoic acid and thyroid hormone induce gene expression through a common response element. Nature 336: 262-265.

Vaessen, M.J., E. Kootwijk, C. Mummery, J. Hilkens, D. Bootsman, and A.G. Van Kessel. 1989. Preferential expression of cellular retinoic acid binding protein in a subpopulation of neural cells in the developing mouse embryo. Differentiation 40: 99-105.

Vaessen, M.J., J.H.C. Meijers, D. Bootsman, and A.G. Van Kessel. 1990. The cellular retinoic-acid-binding protein is expressed in tissues associated with retinoic-acid-induced malformations. Development 110: 371-378.

Wagner, M., C. Thaller, T. Jessell, and G. Eichele. 1990. Polarizing activity and retinoid synthesis in the floor plate of the neural tube. Nature 345: 819-822.

Wanek, N., D.M. Gardiner, K. Muneoka, and S.V. Bryant. 1991. Conversion by retinoic acid of anterior cells into ZPA cells in the chick wing bud. Nature 350: 81-83.

Yamada, T., M. Placzek, H. Tanaka, J. Dodd, and T.M. Jessell. 1991. Control of cell pattern in the developing nervous system: Polarizing activity of the floor plate and notochord. Cell 64: 635-647.

Zelent, A., A. Krust, M. Petkovich, P. Kastner, and P. Chambon. 1989. Cloning of murine $\alpha$ and $\beta$ retinoic acid receptors and a novel receptor $\gamma$ predominantly expressed in skin. Nature 339: 714-717. 


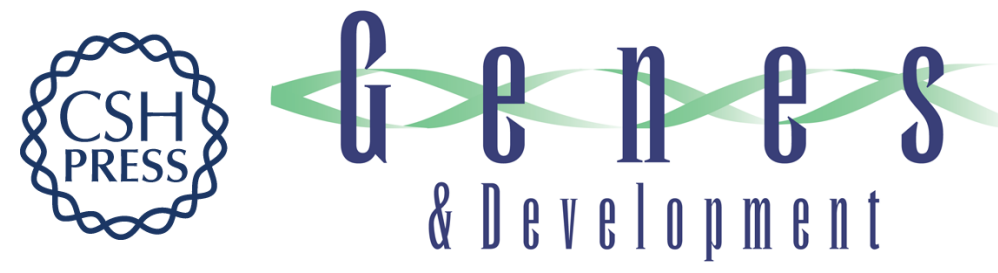

\title{
Expression of a retinoic acid response element-hsplac Z transgene defines specific domains of transcriptional activity during mouse embryogenesis.
}

\author{
J Rossant, R Zirngibl, D Cado, et al.
}

Genes Dev. 1991, 5:

Access the most recent version at doi:10.1101/gad.5.8.1333

References This article cites 65 articles, 25 of which can be accessed free at: http://genesdev.cshlp.org/content/5/8/1333.full.html\#ref-list-1

\section{License}

Email Alerting Service

Receive free email alerts when new articles cite this article - sign up in the box at the top right corner of the article or click here.

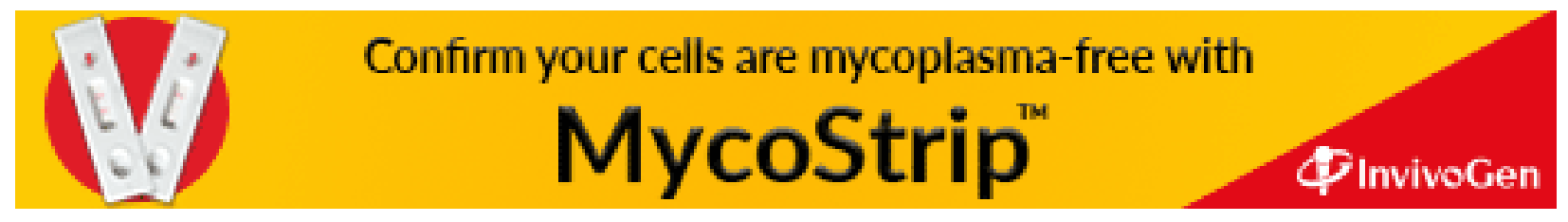

